\title{
AQUELLOS HERMANOS NUESTROS... CIUDADANÍA Y EXCLUSIÓN EN LOS TERRITORIOS CONQUISTADOS
}

\author{
Erika Pani* \\ El Colegio de México
}

\begin{abstract}
G $\mathrm{n}$ marzo de 2017, en respuesta al venenoso discurso antimexicano de quien se había convertido en presidente de Estados Unidos unos meses antes, el abogado Guillermo Hamdan Castro, acompañado por una de las figuras más emblemáticas de la izquierda mexicana, Cuauhtémoc Cárdenas, anunciaba que presentaría una demanda legal para anular la cesión territorial acordada en el Tratado Guadalupe Hidalgo en 1848. ${ }^{1}$ Esta propuesta de invalidar "los acuerdos firmados por el entonces
\end{abstract}

Fecha de recepción: 19 de agosto de 2019

Fecha de aceptación: 7 de noviembre de 2019

\footnotetext{
"Escribí este artículo en el marco del proyecto conjunto CSIC-CCHSCOLMEX-2016-2018, "Raza, racismo y xenofobia: aproximaciones desde la biología, la antropología y la historia”. Agradezco el impulso de sus directores, Consuelo Naranjo y Pablo Yankelevich, la generosidad de Pablo Mijangos y Rebecca Scott, y las sugerencias y comentarios de Kif Augustine-Adams y los participantes de la mesa que organizó para la reunión de la Law and Society Association de junio de 2017, en la que presenté una primera versión de este texto.

${ }^{1}$ Justino Miranda, "Promueve Cárdenas demanda para anular cesión de territorio a EU”, El Universal (10 mar. 2017).
} 
presidente 'traidor a la patria', Antonio López de Santa Anna", 2 adolece de inexactitudes históricas y tiene pocas posibilidades de éxito. No obstante, refleja fielmente el trauma que representa, en el imaginario mexicano, la guerra con Estados Unidos, incluso a 150 años de distancia. El conflicto que iniciara tramposamente el presidente James K. Polk, cuando en 1846 envió tropas a un territorio cuya posesión legítima se disputaban las dos repúblicas, se convirtió en una tragedia nacional. La invasión fue condenada por quienes la vivieron como una guerra "de conquista", profundamente injusta, que repugnaba al "espíritu del siglo" y desmerecía a un pueblo que alardeaba de ser "cristiano" y "republicano". Posteriormente fue censurada como expresión del nefasto imperialismo yanqui. Representa un recuerdo doloroso, que los mexicanos han preferido reprimir. De ahí que, como ha escrito Josefina Z. Vázquez, la producción historiográfica no haya dado cuenta, hasta recientemente, de la complejidad y el alcance de la guerra y de sus repercusiones. ${ }^{3}$

2 Jaime Luis Brito, "Cárdenas y abogado presentan predemanda para recuperar territorio mexicano perdido ante EU”, Proceso (9 mar. 2017). El presidente de México en 1848 era Manuel de la Peña y Peña. El tratado fue firmado en febrero de 1848 por quienes lo negociaron (Miguel Atristáin, Bernardo Couto, Luis G. Cuevas y Nicholas P. Trist), y tras ser modificado por el Senado estadounidense, por el presidente Peña, el ministro de Relaciones, Luis de la Rosa, y los comisionados del gobierno estadounidense, Ambrose Servier y Nathan Clifford, en Querétaro, en mayo de ese mismo año.

${ }^{3}$ Mariano Otero, "Comunicación que sobre las negociaciones diplomáticas habidas en la Casa de Alfaro, entre los Plenipotenciarios de los Estados Unidos y México, dirigió al Excmo. Sr. Gobernador de Jalisco, el C. Mariano Otero, diputado de aquel estado", Toluca, 16 de septiembre de 1847, en Algunos documentos, pp. 69-72. VÁzQUEz, "El origen”, y, para la historiografía estadounidense, Van Wagenen, The Forgotten. En los últimos años, el debate historiográfico se ha enriquecido: Granados, Sueñan las piedras; Reséndez, Changing; Francaviglia y Richmond (eds.), Dueling Eagles; Delay, War; Herrera Serna (coord.), México; Vázquez (coord.), México; Vázquez, La intervención; Greenberg, A Wicked; Guardino, The Dead. 
Resultó devastadora la eficacia con que los invasores ocuparon el Norte Lejano y subyugaron a los ejércitos mexicanos, menos por la falta de arrojo de éstos y la sofisticación estratégica de aquéllos que por estar los mexicanos mal armados, pertrechados y alimentados. ${ }^{4}$ Mientras el ejército de Zachary Taylor avanzaba penosamente desde el norte, las tropas al mando de Stephen Kearny ocuparon, sin mayores contratiempos, Nuevo México y California. En marzo de 1847, a menos de un año de la declaración de guerra, el general Winfield Scott desembarcaba en Veracruz y emprendía la ruta de Cortés hacia el altiplano. A principios de septiembre, sus soldados estaban apostados en las afueras de la capital mexicana. La avasalladora victoria militar de Estados Unidos impuso el tono a unas negociaciones en dos tiempos -en septiembre de 1847 y febrero de 1848-, atormentadas y asimétricas. Su resultado más trascendente fue la pérdida territorial: México reconoció la anexión de Texas y cedió a su vecino lo que hoy son los estados de California, Nevada, Nuevo México, Utah y partes de Arizona, Colorado, Oklahoma y Wyoming.

Desde entonces, los mexicanos -políticos, historiadores y ciudadanos de a pie- hemos llorado la pérdida de más de $1300000 \mathrm{~km}^{2}$ del territorio nacional. El destino de los 100000 mexicanos que se quedaron del otro lado de la nueva frontera -mezcla heterogénea de grupos indígenas locales y colonos provenientes del centro del antiguo virreinato- ha llamado menos la atención. ${ }^{5}$ Sin embargo, la suerte de los compatriotas que dejaron de serlo inspiró grandes preocupaciones durante las negociaciones del tratado y las acaloradas discusiones que desató el acuerdo de paz. Del otro lado de la frontera el estatus de los mexicanos que permanecieron en los territorios

\footnotetext{
${ }^{4}$ Guardino, The Dead, pp. 1-30; 123-158.

${ }^{5}$ Aunque recientemente han sido objeto de investigaciones muy interesantes. Véanse, por ejemplo, González de la VARA, "El traslado”; Hernández, Mexican; Pubols, The Father.
} 
conquistados siguió siendo un asunto contencioso años después de concluida la guerra.

Nos interesa indagar aquí cómo los habitantes de los territorios perdidos dejaron de ser mexicanos. No nos ocuparemos de la construcción de una identidad mexicano-americana, ni de las formas en que californios y nuevomexicanos vivieron la guerra, su desenlace y sus secuelas, ni siquiera -a pesar de tratarse de un proceso determinante- de las consecuencias materiales de la cesión territorial, de cómo afectó, a corto y mediano plazo, los derechos de propiedad de quienes permanecieron del otro lado. Otros colegas han tratado estos temas de forma muy competente. ${ }^{6}$ Pretendemos en cambio explorar el paisaje legal que enmarcó un cambio de jurisdicción que convertiría a los habitantes de los antiguos territorios mexicanos a un tiempo en ciudadanos estadounidenses y, como describiera Juan Nepomuceno Seguín, patriota tejano arrepentido, en "extranjeros en la propia patria"? El artículo se centrará en las formas en que se definieron la pertenencia política y el estatus de los habitantes de estos territorios, en el marco de las negociaciones entre dos naciones en guerra $y$, posteriormente, sobre el terreno, por medio de la ley, de su ejecución y de la resolución judicial de controversias.

\section{Conquista por tratado}

Para enero de 1847, la expansión que ambicionaban la mayoría de los estadounidenses -la transformación de Estados Unidos en potencia continental, prolongándose su territorio hasta el Pacífico- era un hecho consumado. No obstante, James K. Polk, el presidente que arteramente había planeado un incidente mortífero en la frontera para provocar la guerra, insistiría, a pesar de

6 Reséndez, Changing; Griswold del Castillo, The Treaty; De León, They Called Them; Montejano, Anglos.

7 La expresión de Seguín fue retomada por Weber para su antología de textos mexicanoamericanos; Weber, Foreigners. 
lo contundente de la victoria militar, en una "paz honorable", en la que México reconociera, en un documento legal, la cesión del territorio. Empero, la prolongación de la guerra desestabilizaba la política estadounidense. Quienes se oponían a la expansión de la esclavitud en los territorios conquistados exigieron que el Congreso la prohibiera. Al vincularse a la esclavitud con la conducción de la guerra primero, con la organización de los territorios conquistados después, se colocó en el centro del debate legislativo la cuestión más corrosiva y perturbadora de la política federal. Por otra parte, un grupo pequeño pero escandaloso de políticos y periodistas se movilizaba y, al grito de “¡Todo México!”, clamaba por que Estados Unidos se hiciera de más territorio mexicano. ${ }^{8}$

A pesar de ser, como Polk, miembro del Partido Demócrata, el senador John C. Calhoun fue uno de los críticos más vehementes de la política bélica del presidente. El experimentado político -que había sido vicepresidente y secretario de Estado y de Guerra, y encabezado, en la década de 1830, la campaña por que los estados pudieran "nulificar" disposiciones federales impuestas por mayorías hostiles a los derechos de las minoríasconsideraba que profundizar y alargar la guerra conllevaba un riesgo doble: al llevar la guerra al corazón de México, Estados Unidos se arriesgaba a adquirir territorios poblados por una indeseable "raza mestiza" que sería imposible integrar a una república pensada para el "hombre blanco". Además, apostar por una paz pactada, además de ser un preciosismo, colocaba la decisión de poner fin a la guerra fuera de las manos del gobierno estadounidense y en las del mexicano. ${ }^{9}$

El senador de Carolina del Sur no se equivocaba al predecir que las polémicas en torno a la "cesión mexicana" minarían

${ }^{8}$ BRIngas NostTi, La regeneración.

9 Senator Calhoun, January 4, 1848, Congressional Globe, 29th Congress, 1st Session, pp. 49-53. 
-hasta resquebrajarlos- los cimientos de la convivencia política dentro de la "casa dividida" entre un sur esclavista y un norte libre que era Estados Unidos. Exigir la anuencia explícita y solemne de México a las consecuencias de la derrota, en cambio, no significó reforzar su capacidad de negociación. El gobierno mexicano se percató bien pronto del idealismo que subyacía en este supuesto, estrellándose su concepto de lo que era aceptable con la realidad. El 1o de septiembre de 1847, al pactarse la suspensión de hostilidades con el general Scott, una comisión -compuesta por los generales José Joaquín Herrera e Ignacio Mora y Villamil y los abogados Miguel Atristáin, José Bernardo Couto y Luis G. Cuevas- se sentó a la mesa frente al enviado de Polk, el diplomático Nicholas Trist, con el quimérico mandato de "tratar la paz como si se hubiera triunfado, y como quien puede todavía llevarla adelante con ventaja". ${ }^{10}$ Si la fortuna había favorecido a la república del norte, la justicia estaba con la del sur. Los principios del orden republicano que distinguía al Nuevo Mundo del Viejo -y no el peso de las circunstancias- debían articular el acuerdo que pondría fin a la guerra.

Los comisionados mexicanos ofrecieron que su gobierno reconociera la independencia y anexión de Texas -cuyos "hijos ingratos" habían traicionado a la patria diez años atrás-, pero no que su frontera estuviera en el río Bravo, lo que hubiera legitimado la provocación de Polk. El puerto de San Francisco podía conferirse a Estados Unidos "en calidad de factoría", pero no podía sacrificarse un palmo de territorio, patrimonio

10 "Puntos que deberán tratarse en las conferencias con el Comisionado de los Estados Unidos y que deberán servir de bases a los de México, propuestos al Excmo. Sr. Presidente por el Ministro de Relaciones y aprobados por S. E. en Junta de Ministros", 24 de agosto, 1847; “Instrucciones para los comisionados mexicanos, acordadas en Juntas de Ministros de 25 de agosto de 1847, en vista de las propuestas hechas por el comisionado de Estados Unidos", 30 de agosto de 1847, en Castillo Nájera, El Tratado de Guadalupe, p. 41, Apéndice, pp. 53-55; 63-65. 
irrenunciable de la nación soberana. Mucho menos podían entregarse al vecino agresivo a quienes poblaban estas regiones. En enero había estallado una rebelión en Nuevo México, prueba de que quienes habitaban en esa alejada provincia querían seguir perteneciendo a "la familia mexicana". ${ }^{11}$ Perdida la guerra, los comisionados intentaron salvaguardar, para la posteridad, algo del honor de la nación derrotada: exigieron que el tratado fijara "las causales de la guerra” y "por qué derecho y con qué intención” Estados Unidos quería hacerse de más territorio. ${ }^{12}$

Dentro del estrechísimo espacio de maniobra que ofrecían las negociaciones diplomáticas, los mexicanos fincaron sus argumentos en principios intangibles y fundamentales: la dignidad nacional y los derechos de quien había sido agredido sin provocación. En cambio, Trist tenía objetivos pedestres, claros y concretos: el reconocimiento, por parte del gobierno mexicano, de la anexión de Texas -hasta el río Bravo-, la cesión de territorios extensos -Alta y Baja California, Nuevo México- y el paso por el istmo de Tehuantepec, a cambio de entre 15 y 20 millones de dólares, de los cuales 3 se reservarían para satisfacer las reclamaciones de ciudadanos estadounidenses. ${ }^{13}$ No había acuerdo posible: la postura de Trist obligaba al gobierno mexicano a escoger "entre esa cesión y su muerte", entre "la violencia" y la "humillación”. ${ }^{14}$ El proceso de negociación se desmoronó, se rompió la tregua y las tropas estadounidenses ocuparon la ciudad de México.

A principios de 1848, ambas partes regresaron a la mesa de negociación. Las circunstancias imprimían mayor urgencia a su misión. El gobierno de los liberales moderados, refugiado en Querétaro, se hallaba atenazado por su impotencia frente a la

11 “Puntos", en Castillo Nájera, El Tratado de Guadalupe, pp. 54-55.

12 "Puntos", en Castillo Nájera, El Tratado de Guadalupe, pp. 54-55.

${ }^{13}$ Greenberg, $A$ Wicked, 3511/7208 (versión electrónica); Griswold DeL CAstillo, The Treaty, pp. 23-24.

14 "Instrucciones", en Castillo Nájera, El Tratado de Guadalupe, p. 74. 
ocupación militar, la falta de recursos, el descontento en el campo y la agitación provocada por quienes -desde gobernadores radicales como Melchor Ocampo hasta guerrilleros conservadores como el sacerdote español Celedonio Jarauta- ${ }^{15}$ llamaban a proseguir la guerra. El gobierno de Manuel de la Peña y Peña optó por asumir las pérdidas antes de que éstas se acrecentaran. Por su parte, en noviembre, el presidente Polk, frustrado con el fracaso de las negociaciones, desconcertado -y cautivado- por las reivindicaciones de los expansionistas radicales, profundamente irritado por la censura whig y las confrontaciones que engendraba el debate en torno a la esclavitud, cesó a Trist y le ordenó que regresara a Washington.

En contra de las directivas de su gobierno, el comisionado estadounidense buscó poner fin al conflicto, poniendo de nuevo sobre la mesa los términos establecidos previamente -apenas reduciendo, motu proprio, el monto de la indemnización, y conformándose con sólo una de las Californias. La resolución diplomática del conflicto resultó de la desesperación del gobierno mexicano y de lo que Amy Greenberg ha descrito como el "compromiso con la justicia" del agente estadounidense. ${ }^{16}$ Tras las afanosas -e infructuosas- negociaciones de septiembre, las de principios de 1848 avanzaron con sorprendente celeridad. El 2 de febrero, Trist y los tres abogados mexicanos -los militares se habían retirado de la comisión- firmaron, a la sombra de la basílica de Guadalupe, el Tratado de Paz, Amistad, Límites y Arreglo Definitivo entre los Estados Unidos Mexicanos y los Estados Unidos de América.

Resignados a perder una extensa porción del territorio nacional, los apoderados mexicanos intentaron proteger los intereses y el bienestar de los connacionales afectados. Exigieron el

15 Sobre la efervescencia agrarista véase FALcón, "En medio"; Levinson, Wars Within. Sobre Jarauta, Molina, La pasión.

16 Greenberg, $A$ Wicked, 3536/ 7208; Griswold del Castillo, The Treaty, p. 36. 
reconocimiento de los títulos de tierras otorgados por autoridades españolas y mexicanas -incluso en Texas, donde muchos se habían invalidado tras la independencia de la provincia en 1836-, el respeto al derecho de propiedad -individual o corporativa-, la protección de la religión católica-manteniéndose las comunicaciones “francas y libres” con las autoridades eclesiásticas, aunque éstas permanecieran en México- y una indemnización por los males que habían padecido tantas familias. Lograron así introducir, en la versión final del tratado, algunas prescripciones para proteger los derechos -civiles, religiosos y eventualmente políticos- de los mexicanos que quedarían bajo jurisdicción estadounidense.

De este modo, se estableció que los habitantes de los territorios perdidos podían quedarse en Estados Unidos o trasladarse a México, convertirse en estadounidenses o seguir siendo mexicanos -elección que tenían que hacer dentro de un año, a partir de la ratificación del acuerdo-. En ambos casos, sus propiedades serían "respetadas inviolablemente”. Quienes optaran por convertirse en ciudadanos estadounidenses, serían "incorporados” y “admitidos” a la Unión "lo más pronto posible”. En cuanto a sus derechos políticos, su "condición debía ser igual a la de los habitantes de los otros territorios [...] y tan buena, por lo menos, como la de los habitantes de la Luisiana y las Floridas", cuando estas regiones habían sido cedidas a Estados Unidos. En aras de hacer algo también por los habitantes de los estados mexicanos del norte, que con el desenlace de la guerra se transformaban en estados fronterizos, el tratado obligaba al gobierno estadounidense a "contener" los ataques de las "tribus salvajes" que quedaban bajo su jurisdicción, y cuyos asaltos tanto agraviaban a estas poblaciones. ${ }^{17}$ Los promotores del acuerdo de

17 Artículos VIII-XI. Griswold del Castillo, The Treaty, es el estudio de referencia sobre la aplicación del tratado y su fracaso en cuanto a la protección de los mexicanos. Véase también Chacón Gómez, "The intended”. Para los límites y alcances de un tratado de adquisición territorial en E. U. (el de 
Guadalupe Hidalgo dirían incluso que el que la línea fronteriza se desplazara hacia el sur traería consigo la "ventaja incalculable" de llevar a los estados del norte a colindar con una "nación civilizada”, en lugar de con un desierto plagado de tribus bárbaras. ${ }^{18}$

Estos artículos, lo sabemos ahora, no aseguraron la protección efectiva de los mexicanos que quedaron de uno y otro lado de la frontera. Incluso, el que prescribía que Estados Unidos impidiera las incursiones apaches y comanches se abrogó pocos años después, con el Tratado de la Mesilla (1854). Representaron, sin embargo, un logro en circunstancias poco favorables. En palabras de los comisionados, el acuerdo que habían labrado -con la colaboración del "excelente Sr. Trist"- no hacía sino "reducir a formas escritas el resultado final de la guerra". Ante la "gran desgracia" que significaban la derrota militar y la pérdida territorial, se había logrado que el tratado no incluyera ninguna estipulación "de perpetuo gravamen y de ignominia". Las negociaciones habían evitado un mayor quebranto y salvaban, hasta donde era posible, "las condiciones de aquellos hermanos nuestros" que quedaban bajo la autoridad del gobierno estadounidense, como ciudadanos iguales y no como súbditos conquistados. ${ }^{19}$

El Senado estadounidense, responsable, como el mexicano, de ratificar el texto elaborado por los negociadores, decidió enmendarlo antes de aprobarlo. Eliminó el artículo X, que validaba las concesiones de tierra hechas por las autoridades novohispanas o mexicanas en Texas que se habían visto afectadas por

Luisiana de 1803) como garante del acceso a los derechos ciudadanos de un grupo vulnerable -en este caso, la población libre de color de Nueva Orleansvéase Sсотт, “Asserting”.

18 "Comisión de Relaciones, Cámara de diputados", Querétaro, 13 de mayo de 1848, en Algunos documentos, pp. 192-204, p. 199, 201.

19 "Exposición de motivos presentada por los comisionados mexicanos", Ciudad de México, 1ํ de marzo de 1848, en Algunos documentos, pp. 139-168, pp. 139-140. 
las "desavenencias" entre los gobiernos mexicano y texano a partir de 1836. Los legisladores alegaron que era la "gloria" de Estados Unidos el que no existiera, en ese país, "poder humano" que pudiera privar a los individuos -como aquellos que de buena fe habían comprado tierras en Texas- de su propiedad para transferirla a otro. Más allá de esta modificación significativa, que representaba un descalabro para los mexicanos, las demás reformas al texto del tratado fueron presentadas por el gobierno estadounidense como ajustes menores, correcciones de forma y no de fondo.

Los senadores consideraron que el Artículo IX era redundante, pretencioso y barroco. Como explicaba el secretario de Estado James Buchanan a su contraparte en México, Luis de la Rosa, la protección de la libertad, propiedad y libertad de cultos de los habitantes del territorio sería producto de "la naturaleza y carácter mismo de nuestras instituciones", no de las estipulaciones de un tratado. ${ }^{20}$ Por lo tanto, los legisladores estadounidenses habían reescrito esta disposición en el lenguaje de los "sanos precedentes” contenidos en los tratados de cesión territorial firmados con Francia y España. Se añadió, además, que los habitantes de los territorios conquistados serían admitidos dentro de la Unión "en el momento adecuado (a juicio del Congreso de los Estados Unidos)”. ${ }^{21}$

Al recibir el gobierno de Querétaro el texto revisado del tratado, lo sometió al Senado. Muchos legisladores mexicanos cuestionaron duramente el instrumento legal que debía poner fin a la guerra. Los liberales más radicales, "miembros del Partido Puro o Progresista” convencidos de que México debía prolongar la resistencia, insistieron en que su resultado final no

20 James Buchanan al secretario de Relaciones Exteriores de la República Mexicana, Washington, 18 de marzo de 1848, Ex. Doc. No. 50, 30 Congress, $2^{\text {nd }}$ Session, 1849, p. 45. Todas las traducciones son mías.

21 "Treaty as amended by the Senate", en Ex. Doc. No. 50, 30th Congress, $2^{\text {nd }}$ Session, 1849, p. 32. 
sólo era "altamente oneroso, inconveniente y degradante", ${ }^{22}$ sino que era inmoral e ilegal. Los mexicanos habían optado por un régimen político que no facultaba al gobierno federal a ceder "un palmo" del territorio nacional. Era inadmisible que abandonara a quienes habitaban los territorios conquistados al enemigo y, peor aún, que los "vendiera” como si fueran "una manada de ovejas o una partida de esclavos”. ${ }^{23}$ Las monarquías del Viejo Mundo podían intercambiar súbditos y territorio con un plumazo, pero era aberrante que pretendiera hacerlo una república federal. Cualquier cesión, traslación o venta de territorio traicionaba al pueblo del que el gobierno era sirviente y violaba la soberanía de los estados que, sobre la base de su "natural y recíproca independencia”, habían constituido una Unión para “trabajar de acuerdo en el bien y conservación común [...] jamás para ser absolutamente excluidos de sus ventajas, segregándolos de la comunión para unirlos a otra”. ${ }^{24}$

Según los diputados que desde sus curules denostaron las negociaciones de paz, las autoridades federales se comportaban como los socios de una compañía que pretendían "seguir girando" los fondos de los asociados a quienes habían excluido

22 "Exposición dirigida por varios señores diputados a la Corte Suprema de Justicia, intentando el recurso establecido por el artículo 23 del Acta de Reformas, para que se someta el Tratado de paz al examen de las legislaturas de los estados", Querétaro, 19 de mayo de 1848, en Algunos documentos, pp. 248-261, p. 248.

23 "Exposición o programa de los Diputados pertenecientes al Partido Puro o Progresista sobre la presente guerra, con motivo de una proposición del Sr. Otero e imputaciones de ciertos periódicos que se publican en la capital, bajo la influencia del conquistador, y que se dejan correr libremente por el actual gobierno de la Unión", Querétaro, diciembre de 1847, en Algunos documentos, pp. 97 y 102.

24 "Exposición o programa", en Algunos documentos, p. 97. También Mariano Otero -que posteriormente, como secretario de Estado, sería responsable de ejecutar las disposiciones del tratado-insistiría en que la intervención de los Estados en el acuerdo de paz estaba "no sólo autorizada", sino que era "exigida". Otero, "Comunicación", en Algunos documentos, p. 85. 
injusta y unilateralmente. ${ }^{25}$ Reconocer su legitimidad equivalía a admitir que existía "en el poder central el derecho de vender [a los estados] contra su voluntad a una potencia extraña" ${ }^{26} \mathrm{La}$ vergonzosa paz de Guadalupe Hidalgo aseguraba la extinción de la nacionalidad mexicana, de la existencia política de la república. ${ }^{27}$ Separado tan solo por "una línea matemática" de Estados Unidos, de cuyas intenciones, carácter y capacidades no se podía ya dudar, México perdería el resto de su territorio en menos de 15 años, "sin tener ni medios ni gloria para combatir". Era patente que los tratados y el derecho no valían nada cuando se ponían "de por medio el interés y la ambición de los pueblos". El acuerdo binacional no era una "garantía" sino una "irrisión". 28 Como preconizaba indignado el político yucateco y antiguo ministro de Relaciones, Manuel Crescencio Rejón, "nuestra raza $[\ldots]$, nuestro pobre pueblo tendrá que andar errante [...] [D]escendientes casi todos nosotros de los indios, el pueblo norteamericano nos abomina, sus oradores nos desprecian aun en los discursos que reconocen la justicia de nuestra causa". ${ }^{29}$

A la retórica flamígera de estos patriotas exasperados, a su concepción de la nación como asociación voluntaria, y a su visión apocalíptica de la posguerra, los abogados del gobierno opusieron un discurso resignado, una idea de la nación como un todo orgánico, cuya soberanía podía articularse, sin reservas, mediante los órganos de gobierno y una visión del futuro paradójicamente, al mismo tiempo, menos pesimista y más desencantada. Ni los comisionados que negociaron con Trist, ni los miembros del gobierno al que representaban arguyeron que el tratado fuera cosa buena; no obstante, negaron que el

25 Otero, "Comunicación”, en Algunos documentos, pp. 97-98.

26 "Exposición”, en Algunos documentos, pp. 97-98.

27 Otero, “Comunicación”, "Exposición”, en Algunos documentos, pp. 68, $85,101$.

28 Otero, “Comunicación”, en Algunos documentos, pp. 79-80.

29 Rejón, “Observaciones”, en Algunos documentos, p. 327. 
país tuviera la opción de evitar el desastre y seguir peleando. Los nuevos límites de la nación habían sido "trazados por la espada" y el conquistador era "soberano de hecho". Tanto los estados -cuyos derechos y autoridad se defendía con tanta vehemencia-como los mexicanos habían mostrado ser incapaces de sostener el esfuerzo bélico. El gobierno creía no equivocarse al afirmar que la opinión pública calificaba de necesaria la paz, pues no se había movilizado de forma sostenida y suficiente para sostener la guerra.

Como se ha visto, los comisionados afirmaron que habían afianzado, hasta donde les había sido posible, garantías para los mexicanos que quedaban "del otro lado". Negaron haber realizado algún "negocio de venta": "ni el gobierno mexicano [había vendido], ni el gobierno de Estados Unidos” había comprado tierras y hombres. El Norte Lejano se había perdido en la guerra. La indemnización debía compensar, mínimamente, las desgracias que ésta había acarreado. El negar la facultad al Ejecutivo de negociar la paz era "disputarle el derecho de disminuir el quebranto de la nación, poniendo en duda su derecho de rehacerse, por la única vía posible, de la porción más granada de lo que estaba perdido". ${ }^{30}$ Los críticos del tratado habían denunciado al derecho de gentes como un "sarcasmo", con el que se pretendía adornar lo que no eran sino las acciones abusivas del más fuerte. Sus artífices, en cambio, citaron copiosamente trabajos como los de Emer de Vattel, para justificar que el Ejecutivo actuara de manera expedita y autónoma para acordar los términos de paz y que, en "caso de urgente necesidad", como el cirujano que amputa un miembro enfermo, separara de la nación a una de sus partes integrantes para preservar la "salud pública". ${ }^{11}$

30 "Exposición de motivos presentada por los comisionados de México", 1을 marzo de 1848, en Algunos documentos, pp. 139-168, pp. 161, 142-143.

31 "Exposición con que el Ministro de Relaciones presenta al Congreso Nacional el Tratado de Paz", Querétaro, 9 de mayo de 1848, en Algunos documentos, pp. 184, 186. 
La lectura de los moderados, apegada a los textos dieciochescos, equiparaba la política del gobierno con la acción legítima del príncipe, lo que no dejaba de infundirles cierto tufo de Antiguo Régimen. Al contrario, quienes condenaban el tratado concebían a la nación de manera más sofisticada, más moderna y más democrática: era producto de un pacto voluntario. Alegaban que la delegación de la soberanía era condicional y limitada, y que los estados federados eran las entidades privilegiadas para su articulación. Sus contrincantes pensaban a la nación como un todo orgánico pero inerte cuyo portavoz, en una disputa internacional, era el jefe del Ejecutivo. La soberanía nacional se concebía como mayor a la de las partes que la componían y su delegación lo suficientemente incondicional para permitir al Estado cercenar el territorio y disponer de su población, independientemente de la voluntad de quienes habitaban estos espacios.

Por otra parte, la visión del futuro de los defensores del tratado era menos oscura que la de sus contrincantes, convencidos de que poco faltaba para que México desapareciera "del catálogo de las naciones". Alegaron que la "dura lección" que habían vivido serviría a los mexicanos para "entrar en buen consejo" y curarse "de antiguos vicios" ${ }^{32}$ Otros creyeron -y el tiempo les daría la razón, aunque efímeramente y poco más de una década más tarde- que Estados Unidos, al transformarse en una potencia continental, introducía en su seno elementos de disolución: la "gran nación" se dividiría en dos. La "parte meridional", con la que México compartiría una frontera, estaría poblada no ya exclusivamente por la "raza anglosajona" sino por una más "cruzada". Sería "mucho menos terrible" para su vecina. Podría servir incluso "de barrera provechosa" entre anglosajones e hispanoamericanos. ${ }^{33} \mathrm{~A}$ pesar de lo severo de las críticas contra el

32 "Exposición”, en Algunos documentos, pp. 167-168.

33 “Comisión de Relaciones, Cámara de diputados”, Querétaro, 13 de mayo de 1848, en Algunos documentos, pp. 192-204. 
Tratado de Guadalupe Hidalgo, el Senado mexicano votó para ratificarlo el 30 de mayo de 1848,33 votos contra $4,{ }^{34}$ elevando a rango de ley un acuerdo que transformaría, eventualmente, a ciudadanos mexicanos en extranjeros.

\section{Pertenencias resbaladizas}

Los puros que se opusieron a las negociaciones de paz pintaron la ratificación del Tratado de Guadalupe Hidalgo como una tragedia irredimible: la nación había sacrificado parte de su territorio, su honor íntegro y, seguramente, su porvenir. Sin embargo, como instrumento legal, el convenio registra el carácter inestable y ambiguo de la pertenencia política de la época y acompaña procesos históricos menos inusuales de lo que sugiere la dimensión trágica de su legado. Incluso, la manera en que el tratado resolvía las cuestiones de ciudadanía en los territorios perdidos coincidía con la forma en que los puros pensaban la comunidad política, como una asociación engendrada por la voluntad de sus miembros.

Esta concepción era producto de la revolución mental que habían acarreado, en América, las revoluciones de independencia. Se articuló en torno a las palabras clave de la revolución -libertad, derechos, soberanía popular, opinión pública, voluntad general, constitución-, que a un tiempo apuntalaron la legitimidad política de las nuevas naciones y animaron -contenciosas, volátiles, corrosivas- una política bullangera, fronteras movedizas y lealtades inestables..$^{35}$ Durante las primeras décadas del siglo xIX, en todo el continente y bajo las banderas de la libertad y del pueblo, las rebeliones, los revolucionarios itinerantes y la

34 Sordo Cedeño, "El Congreso", p. 102.

35 Morgan, Inventing; Sabato, La politica; Palti, El tiempo. Sobre la inestabilidad de la geografía política, véase ST. JoHN, “The Unpredictable”, p. 57. 
defensa de la autonomía regional pusieron de manifiesto la fragilidad de los vínculos políticos.

Eric S. Schlereth ha descrito cómo la convicción de que la filiación política era voluntaria, de que cada individuo gozaba de un derecho natural y absoluto a la expatriación, alimentó tanto la colonización de Texas como su rebelión contra el gobierno mexicano. ${ }^{36}$ En 1841, cuando José Antonio Navarro, patriota texano capturado durante la expedición de la república rebelde a Nuevo México, fue llevado a la ciudad de México para ser juzgado por traición a la patria, rechazó los cargos en su contra. Defendió sus acciones y las de sus compatriotas -tanto anglos como tejanos- apelando a los principios esgrimidos por la revolución que había fracturado a la monarquía católica. Citó prolijamente el tratado del sevillano José Félix Reinoso, que en 1816 defendiera a los afrancesados que habían colaborado con Napoleón tras su invasión de la península. ${ }^{37}$ La rebelión de Texas, alegó Navarro, había sido la consecuencia lógica y una respuesta razonable ante la incapacidad del gobierno mexicano, que no había podido defender a la provincia de los ataques de los "bárbaros" y su quebranto del pacto federal. ${ }^{38}$ De manera similar, la proclamación de un régimen centralista en 1836 provocó que un grupo de políticos californios proclamara que su estado era "libre" y que cortaba "todas sus relaciones con México hasta que deje de ser oprimido". Para los californios que proclamaban "federación o muerte", el amor a la patria grande no eclipsaba su compromiso con el sistema político federal. ${ }^{39}$

\footnotetext{
36 Schlereth, "Privileges"; "Voluntary".

37 Examen.

38 Reséndez (ed.), A Texas Patriot.

39 Declaración de la Alta California, 7 de noviembre, 1836, en The Pronunciamiento in Independent Mexico, 1821-1876, disponible en https://arts. st-andrews.ac.uk/pronunciamientos/regions.php? $\mathrm{r}=29 \&$ pid=1588 (visitado 15 de mayo de 2017).
} 
La guerra entre México y Estados Unidos vino a sacudir sentidos de identidad y lealtad que eran ya endebles. Si las prescripciones que imponía el patriotismo en tiempos de guerra eran relativamente claras, las cosas sobre el terreno eran, como normalmente lo son, mucho más complicadas. Así, al estallar la guerra, uno de los estados mexicanos declaró su neutralidad. Unos meses después, Yucatán se vio rebasado por una violenta rebelión maya. Ante la tremenda "guerra de castas", los políticos que pocos años antes habían promovido la secesión de la península, desesperados, ofrecieron la soberanía yucateca a la potencia que estuviera dispuesta a intervenir militarmente para aplastar a los "salvajes". ${ }^{40} \mathrm{Al}$ final, el gobierno mexicano utilizó una parte de los fondos de la indemnización estadounidense para pacificar, parcialmente, a la península devastada por el levantamiento de los pueblos mayas.

En la estela de la derrota, los mexicanos desgranaron un rosario de recriminaciones. Se denostó la deslealtad de Santa Anna, la pusilanimidad de algunos gobernadores, el egoísmo de la Iglesia y la perfidia de los polkos. El arsenal de las luchas partidistas se vio engrosado por falaces acusaciones de traición. En 1850, por ejemplo, Francisco Suárez Iriarte, presidente del gobierno municipal durante la ocupación, fue acusado de sedición e infidencia por lo que unos describían como el cumplimiento de su responsabilidad como autoridad -el negociar con el ejército de ocupación para garantizar el orden en la ciudad y proteger a sus habitantes-, otros como su colaboración con las fuerzas invasoras, y que el imputado retrataba como su "excesivo entusiasmo" por "los derechos de la humanidad". ${ }^{41}$

La situación en los territorios conquistados del Norte Lejano era incluso más compleja. La enorme distancia, lo que se percibía

40 Sierra O’Reilly, Diario, pp. 116-118. Para un interesante análisis de la naturaleza pragmática del autonomismo yucateco, véase Flores, Soberanía. 41 Suárez Iriarte, Defensa, p. iv; Berge, “A Mexican”; Sánchez de Tagle, “1847”. 
como la indiferencia o incompetencia del gobierno nacional y, en el caso de Nuevo México, el poderoso magnetismo de la dinámica economía estadounidense -que se transmitía por medio de la ruta comercial de Santa Fe-, tensaban los lazos de la nacionalidad y diluían el sentido de pertenencia. ${ }^{42}$ De ahí, quizá, que las tropas invasoras fueran recibidas, más que con agresiones abiertas, con un silencio hostil y expectante. Tanto observadores interesados entonces como algunos historiadores después repararon en la naturaleza relativamente pacífica de la ocupación de Nuevo México y, tras unas breves escaramuzas, también la de la Alta California. ${ }^{43}$ En su afán por establecer rápidamente un dominio eficaz, las tropas invasoras buscaron a un tiempo amedrentar y seducir. Así, Stephen Kearny, comandante de las operaciones en el Oeste, advirtió a la población nuevomexicana que sería "demencia o locura” intentar resistir el imponente poderío de su ejército, pero esbozó también las inmensas bondades del modelo político y económico estadounidense que estaban por establecer. ${ }^{44}$

Al entrar con sus tropas a Santa Fe, el general absolvió a los nuevomexicanos de su lealtad al gobierno mexicano, prometió protegerlos de las depredaciones indias, establecer un gobierno republicano y transformarlos en ciudadanos estadounidenses. Por su parte, Juan Bautista Vigil, que había sustituido al gobernador Manuel Armijo cuando éste se puso al frente de la malograda defensa del territorio, convocó a la población a aceptar el nuevo orden de cosas, utilizando el lenguaje tradicional de la sujeción política. No tocaba a los habitantes del territorio, insistió, determinar "las fronteras de la nación", sino "obedecer a las autoridades establecidas”, independientemente de las

42 Reséndez, Changing; "Getting”.

43 Véase, en cambio, Moyano, "La invasión”; La resistencia; Herrera, "New Mexico".

44 General Stephen W. Kearny, "Proclamation to the People of Santa Fe," August 22, 1846, en Crutchfield, Revolt, pp. 169-170. 
“opiniones privadas" de cada quien. La realidad del poder determinaba su legitimidad: "nadie en el mundo podía resistir el poder del más fuerte". ${ }^{45}$ En presencia de Kearny, el gobernador juró lealtad al gobierno "de Norte América", como lo hicieron también, a nombre de los pueblos que gobernaban, algunos de los alcaldes del territorio, siguiendo la tradición hispana. Así, comentó un testigo, se había "americanizado" la provincia. ${ }^{46}$

En California, Monterey, capital del estado, fue ocupada sin sobresaltos. No obstante, al sur, parte de la población se levantó en armas. En diciembre de 1846, un grupo de californios, bajo el mando de Andrés Pico, hermano del gobernador, venció a las fuerzas estadounidenses en San Pascual. La ascendencia militar de los californios fue efímera. Un mes más tarde, tras las derrotas de San Gabriel y La Mesa, se puso fin a las hostilidades mediante el Tratado de Cahuenga. Este acuerdo imponía a los defensores mexicanos la entrega de sus armas y que regresaran "pacíficamente" a sus hogares y acataran "las leyes y reglamentos de los Estados Unidos”. Debían "asistir y ayudar" a las autoridades del ejército invasor "poniendo al país en un estado de paz y tranquilidad". Los californios no tendrían que jurar lealtad al gobierno de la república del norte sino cuando terminara la guerra, pero gozarían, bajo la ocupación estadounidense, de los "derechos y privilegios" de los ciudadanos de Estados Unidos. ${ }^{47}$

En Nuevo México, la consolidación del dominio del ejército invasor fue menos tersa de lo que se había previsto en un inicio. Un grupo de políticos nuevomexicanos -entre quienes destacaban algunos jefes milicianos como Diego Archuleta- planeó dar

45 Governor Juan Bautista Vigil's Response to Kearney's address, August 19, 1846, en CRutchfield, Revolt, p. 167.

46 Testimonio de Lewis Garrad en McNierney (ed.), Taos, pp. 65-66.

47 Treaty of Campo Cahuenga, January 12, 1847, athttp://www.militarymuseum.org/Cahuenga.html (visitado 17 de mayo de 2017). 
un golpe contra el gobierno de ocupación. Aunque los conspiradores fueron descubiertos y arrestados, en enero de 1847 estalló una rebelión-aparentemente no relacionada con la conspiración- en el norte del territorio. Charles Bent, el comerciante estadounidense de larga experiencia en el territorio -casado con nuevomexicana- que Kearny había nombrado gobernador antes de marchar hacia el Pacífico, fue asesinado y los levantados -nuevomexicanos e indios pueblo-se refugiaron en la Sierra de la Sangre de Cristo. En febrero fueron derrotados tras una sangrienta batalla en Taos. ${ }^{48}$ Como hemos mencionado, el gobierno mexicano interpretó esta rebelión como la obra de patriotas mexicanos. Ésta fue también la postura de los rebeldes, que convocaban a "los defensores del país" a sublevarse para sacudir el "yugo" del "gobierno del extranjero". Invocaban al "Dios el protector de los Indios", implorando les permitiera vencer y recuperar "la libertad que poseíamos en este departamento". ${ }^{9}$

Resultó más difícil interpretar y dotar de sentido a este movimiento para las autoridades nuevomexicanas -nuevas y viejas, militares y civiles, estadounidenses y mexicanas-. El sucesor de Bent, Donaciano Vigil, vástago de una familia de la élite santafesina, antiguo oficial de milicias y político experimentado, alegó que la rebelión carecía de contenido político: no era sino una "guerra" entre la "chusma" y los hombres "honestos y decentes" ${ }^{50}$ Por su parte, los oficiales estadounidenses consideraron que para restablecer el orden tenía que hacerse justicia con celeridad.

Uno de los jefes rebeldes, Pablo Montoya, fue capturado y llevado ante un consejo de guerra. Teniente de milicia, Montoya había sido un protagonista destacado en la rebelión que, diez

48 Crutchfield, Revolt; Herrera, “New Mexico”.

49 "Organization of the Government in New Mexico-Power of the CourtsTreason-Drumhead Court Martial-What did it all tend to?”, en Niles National Register (15 mayo 1847).

50 Proclamation, Santa Fe, January 25, 1847, en McNierney, Taos, pp. 42-43. 
años antes, había sacudido la provincia en la estela de la promulgación de la constitución centralista. Los "cañaderos" del norte del territorio se habían levantado entonces contra imposiciones fiscales y militares que consideraban excesivas. El gobernador nombrado en la ciudad de México, Albino Pérez, había terminado, igual que Bent, muerto por los rebeldes. En 1837, Montoya abandonó la insurrección y actuó como mediador y artífice de lo que terminó siendo la sangrienta pacificación del territorio. ${ }^{51}$ Una década después, no se le presentó una oportunidad similar: los miembros del consejo -todos estadounidenses- determinaron que era culpable de "conducta rebelde" y lo condenaron a morir en la horca. ${ }^{52}$

Tras la ejecución de Montoya, la justicia ordinaria se hizo cargo de los procesos contra los rebeldes. Antonio María Trujillo, un anciano de 75 años, también miliciano e identificado durante el juicio sumario a Montoya como "inspector de armas" de las fuerzas sublevadas, fue acusado de "traición". Había "faltado al respeto" a la autoridad política a la que acababa de adherirse; había hecho la guerra a los Estados Unidos "alevosa, maliciosa y traidoramente". Fue sentenciado a muerte. Sin embargo, la premisa que subyacía en la sentencia -que estos malmandados se habían convertido en ciudadanos estadounidenses por el mero hecho de la ocupación militar- resultaba perturbadora. El corresponsal del periódico Missouri Republican subrayaba el absurdo de que un discurso del general Kearny, pronunciado en medio de un imponente despliegue militar, y un juramento, seguramente proferido con "la reservación mental de quebrantarlo en cuanto fuera conveniente", hubieran transformado a "extranjeros enemigos" en "ciudadanos americanos". ${ }^{53}$

51 Sobre la rebelión de 1837, González de la VARA, "La rebelión de los cañaderos".

52 “Organization”, Niles National Register (15 mayo 1847).

${ }^{33}$ Garrard en McNierney, Taos, pp. 75-76; “Organization”, Niles National Register (15 mayo 1847). 
Interpelados, los miembros del gabinete de Polk rechazaron que la conquista territorial pudiera tener, en automático, tan trascendentales consecuencias. William Marcy, secretario de Guerra, escribió al coronel Sterling Price, jefe de las fuerzas de ocupación, que Nuevo México no se había convertido en parte de Estados Unidos, ni sus habitantes se habían transformado en ciudadanos de este país. Debían obediencia a los conquistadores; podían y debían ser procesados por cometer delitos como el robo y el homicidio. Al levantarse en armas, los revoltosos habían quebrantado el orden, pero no la relación privilegiada que unía a la patria con sus hijos, a los ciudadanos con las autoridades de la República. Sus acciones no podían describirse "correctamente, en términos legales" como traición. ${ }^{54}$

Consecuentemente, cuando otros protagonistas de la rebelión fueron llevados ante el juez de distrito, no fueron procesados por haber cometido traición, el crimen "más atroz de todos los que han ennegrecido los anales de la historia", sino por un delito más prosaico: el homicidio. Éste conllevaba la misma pena -la muerte-, por lo que debe haber servido de pobre consuelo a los reos. ${ }^{55}$ Como precedente judicial, sin embargo, pretendía acotar y simplificar la relación entre las autoridades de ocupación y la población sobre la que mandaban. Posteriormente, el tribunal desechó los cargos en contra de 24 implicados en el levantamiento, por no haber suficiente evidencia en su contra, pero también porque, al final, las autoridades concluyeron que los rebeldes habían actuado como mexicanos, hombres débiles, "bajo la influencia y engañados por hombres que siempre habían ejercido sobre ellos un control tiránico". ${ }^{56}$

54 CRutchfield, Revolt, pp. 103-104.

55 Crutchfield, Revolt, p. 102, pp. 103-104, pp. 106-107.

56 Governor Donaciano Vigil to James Polk, Santa Fe, March 1847, en McNierney, Taos, pp. 78-79. 
Estatus y derechos:

la norma y la adjudicación judicial

Durante la guerra, las autoridades estadounidenses procuraron establecer su dominio sobre un terreno escabroso para asegurar que la población acatara sus disposiciones en un ambiente marcado por la hostilidad, el desprecio y la desconfianza. Los ciudadanos, por su parte, procuraron preservar $-y$ en algunos casos fortalecer-sus intereses, influencia y espacios de maniobra. El fin de la guerra y la ratificación de un tratado que fijaba las bases legales para la integración de la población de los territorios conquistados a una nueva comunidad política no clausuraron la incertidumbre y los desafíos que enfrentaban estos hombres y mujeres. La historiografía ha insistido, con razón, en lo conflictivo del legado del Tratado de Guadalupe Hidalgo, y en la amarga experiencia de despojo y marginación que vivió la población mexicana en Texas desde 1836 y después de 1848 en California y en lo que se había convertido en el Suroeste estadounidense. ${ }^{57}$ La migración, las transformaciones económicas, los conflictos, los desplazamientos y la discriminación que marcaron los años posteriores a la guerra llevaron a algunos mexicanos a "repatriarse" para crear nuevos asentamientos y recrear lazos familiares y comunitarios del lado mexicano de la nueva frontera..$^{58}$

Pero la mayoría de los habitantes de la región permanecieron y perseveraron. Algunos recurrieron, cuando les fue posible, a la legislación y al litigio para robustecer su posición y sus aspiraciones. Por tratarse de acciones que exigían recursos, medios y conocimientos, éstas involucraron las más de las veces a los miembros de la élite local. Sin embargo, las estrategias y argumentos que se desplegaron en estos pleitos estructuraron la

57 Griswold del Castillo, The Treaty; De León, They Called; MontejaNo, Anglos.

${ }^{58}$ González de la Vara, "El traslado"; Hernández, Mexican American; Martínez, "Los dos Laredos"; Tinker Salas, "Los dos Nogales". 
ciudadanía como categoría de inclusión y exclusión en los territorios conquistados y moldearon el estatus legal de los mexicanos que optaron por quedarse. Ameritan, por lo tanto, ser analizados.

Después de 1848, quienes estaban por dejar de ser mexicanos enfrentaron circunstancias distintas dentro del marco legal compartido que establecía el tratado. La dimensión regional resultó determinante: unos días antes de la firma del acuerdo de paz, en el norte de California, unos trabajadores encontraron oro en un aserradero, propiedad del suizo John Sutter. La violenta "fiebre del oro" que desató este hallazgo transformó la economía del mundo y sobrecalentó la local. Atrajo una ola multinacional y multilingüe de buscadores -alrededor de 100000-, que convirtió a los californios en una minoría. Los inmigrantes estadounidenses que se abalanzaron sobre la región buscaron hacerse del poder político: con el ejército, se movilizaron para constituir a California como estado, objetivo que lograron en 1850. En cambio, las condiciones demográficas y económicas de Nuevo México no variaron significativamente con el cambio de jurisdicción: siguió siendo una región aislada, escasamente poblada y pobre, que permaneció bajo la autoridad del gobierno federal hasta 1912. En 1848, 60\% de la población de los territorios perdidos vivía en Nuevo México, y la región concentra, hasta el día de hoy, el mayor número de habitantes de origen mexicano de Estados Unidos. En este contexto, la élite nuevomexicana pudo moverse con mayor facilidad para defender su poder, riqueza y prerrogativas dentro del nuevo orden que sus cofrades en otras regiones que habían sido mexicanas. ${ }^{59}$

Quizá con mayor eficiencia que los tejanos al declararse la independencia de Texas, californios y nuevomexicanos

59 Por lo menos hasta lo que se conoce como la Guerra del Condado Lincoln, a finales de la década de 1870. "Overview”, en González-Berry y Maciel (eds.), The Contested, pp. 12-22. 
contribuyeron a la definición de las bases del gobierno estatal y territorial en la estela del advenimiento de la jurisdicción estadounidense. En febrero de 1850, cuando se reunió la convención territorial de Nuevo México, fue presidida por un sacerdote, Antonio José Martínez. De sus 19 delegados, 13 tenían apellidos hispanos. ${ }^{60}$ No hay razón alguna para asumir que los antiguos mexicanos conformarían un bloque político. El trabajo de Phillip B. Gonzales muestra que al afianzarse el sistema bipartidista estadounidense en el territorio, por medio de los partidos "americano" y "mexicano", los nuevomexicanos participaron activamente en las contiendas políticas a través de ambos partidos, a pesar de que las banderas partidistas se articularon en torno a una referencia explícita al supuesto enfrentamiento entre pobladores antiguos y recientes. ${ }^{61}$

No obstante, los debates de la convención nuevomexicana no registran controversias y sus resoluciones sugieren que la élite del territorio logró conservar normas y jerarquías que beneficiaban a sus miembros en conjunto. El delegado de la asamblea en Washington debía promover que se mantuviera el estatus de territorio: una asamblea electa conviviría con un gobernador designado por el gobierno federal. El representante de Nuevo México también debía asegurar que el legislativo federal tomara medidas para asegurar "el respeto a los contratos entre amos y sirvientes" y afianzar el peonaje -sistema de coerción laboral con el que el gobierno federal no intervendría sino hasta después de la Guerra Civil- ${ }^{62}$ así como para proteger a los habitantes del territorio de "litigios injustos y maliciosos" y de las "incursiones y robos" de los navajos, "tribu merodeadora y salvaje”. Tenía

${ }_{60}$ New Mexico, pp. 1-2. La recurrencia de ciertos apellidos (Armijo, Baca, Otero, Vigil) sugiere que se trataba de una élite pequeña y unida.

${ }^{61}$ Gonzales, "Mexican Party”.

${ }^{62}$ SMITH, "Emancipating". 
además que asegurarse de que las ordenanzas mineras mexicanas se mantuvieran en vigor. ${ }^{63}$

En contraste con la presencia dominante de los nuevomexicanos, de los 48 miembros de la convención constituyente de California, que se reunió entre septiembre y octubre de 1849, sólo siete eran californios, seis de ellos por nacimiento. ${ }^{64}$ Como podía esperarse, tuvieron menos éxito que sus compatriotas nuevomexicanos. Uno de los delegados por San Francisco, William Gwin, nativo de Tennessee, insistiría incluso en que la constitución que discutían no debía pensarse "para los californianos nativos" sino para la "gran población americana” que trabajaba en los campos mineros, y que constituía ya la mayoría de la población. ${ }^{65}$ Los californios no pudieron impedir que se erigiera a California en estado, ni lograron que, como algunos hubieran deseado, la antigua Alta California se dividiera en dos, erigiéndose en un territorio federal en la región del sur. ${ }^{66}$ Pero tanto en el nuevo estado como en el antiguo territorio los miembros de la élite mexicana lograron salvaguardar sus derechos políticos, para ellos y para los suyos.

Tanto California como Nuevo México restringieron el derecho al voto a los "hombres blancos libres", como hacía la mayoría de los estados en esta época. La enmienda que introducía esta restricción en el acta del gobierno territorial fue aprobada unánimemente por los representantes nuevomexicanos, ${ }^{67}$ lo que sugiere que no sólo estaban seguros de su blancura, sino también convencidos de que ésta sería reconocida dentro de

\footnotetext{
63 New Mexico, pp. 10-13.

64 Report, pp. 517-518.

65 Gwin, en Report, p. 16.

66 Carrillo, en Report, pp. 22-23. El delegado por Los Ángeles consideró que, puesto que sus representados no compartían el entusiasmo por constituir un estado, podría dividirse a California con una línea a la altura de San Luis Obispo, manteniendo a un gobierno territorial en el sur. Esto, argüía, no contradecía el que se considerara "tan ciudadano americano" como Gwin.

67 New Mexico, p. 4.
} 
una república que muchos pensaban era patrimonio exclusivo del hombre blanco. Los californios enfrentaron una situación más adversa, al encarar, desde la minoría, a unos políticos recién llegados que procuraron, agresivamente, reforzar el poder e influencia de los protagonistas del expansionismo estadounidense, a costa, de ser necesario, de los antiguos residentes. Así, algunos de los miembros de la constituyente condenaron incluso lo que consideraban era la "doctrina monstruosa" que afirmaba que un tratado podía anular prescripciones constitucionales para transformar - a ciegas- a extranjeros en ciudadanos, y a ciudadanos en votantes. ${ }^{68}$

De forma paralela a su labor constituyente, estos hombres no dudaron en manipular la ley -y, específicamente, los parámetros de la ciudadanía- para legitimar la discriminación y las acciones violentas que se llevaban a cabo en los campamentos mineros para excluir y aislar a los miembros de minorías supuestamente "no blancas"-chinos, mexicanos, chilenos e irlandeses- que, como "extranjeros" no tenían derecho a beneficiarse de la bonanza californiana. ${ }^{69}$ Por medio de sus intervenciones en el debate constitucional, y de su intervención en el texto de la ley fundamental del estado, los miembros de la élite californiana lograron preservar su acceso al poder político, aunque esto no necesariamente repercutió en beneficio de sus antiguos compatriotas, los mexicanos -en su mayoría sonorenses-que recién llegaban a los campos auríferos californianos con la esperanza de volverse ricos.

La mayoría de la asamblea votó por prohibir la inmigración de afroamericanos libres, e intentó excluir del derecho al voto a los indígenas. Enfrentaron, sin embargo, la oposición

68 Botts, en Report, p. 66.

69 George Cosgrave, “A Diplomatic Incident”, pp. 358-362; PitT, Decline; Purcell, ;Muchos! Destaca, entre los esfuerzos para discriminar a los miembros de las minorías étnicas dentro de la esfera económica, el “impuesto a los mineros extranjeros”, que encarecía su participación en la actividad minera. 
de quienes argüían que éstos habían sido reconocidos como ciudadanos por el derecho mexicano, y que por lo tanto las provisiones del tratado de paz impedían que fueran privados de sus derechos políticos. Pablo de la Guerra, miembro de una distinguida familia de Santa Bárbara, puso fin a lo que amenazaba en convertirse en una discusión interminable sobre las posibles interpretaciones de Tratado de Guadalupe Hidalgo y la ambivalencia de la ley y la praxis política mexicanas frente a los indígenas como actores políticos. Arguyó que el negar la ciudadanía a los indios de California sería fundamentalmente injusto, puesto que pagaban impuestos. Además, muchos de los prohombres de la república mexicana pertenecían a la "raza indígena".$^{70}$ Aunque De la Guerra insistió en que los indios que soportaban la misma carga fiscal que los ciudadanos no indios debían gozar de "privilegios iguales", no objetó que se introdujera la palabra "blanco" en el artículo constitucional que definía el derecho al sufragio. Esta restricción racial no representaba un problema, siempre que se "comprendiera perfectamente su verdadero significado", pues

[...] muchos ciudadanos de California han recibido, por parte de la naturaleza, una piel muy oscura; sin embargo, hasta ahora han podido votar, y no sólo eso, han desempeñado los primeros cargos de la administración pública. Sería muy injusto privarlos del privilegio de la ciudadanía, sólo porque la naturaleza no los hizo blancos. Pero si, con el término "blanco", se pretende excluir a la raza africana, es entonces correcto y satisfactorio. ${ }^{71}$

70 De la Guerra (identificado, equivocadamente, por su apellido materno, Noriega, que se registra, equivocadamente también, como Noriego), en Report, pp. 63, p. 70.

${ }_{71}$ De la Guerra, en Report, p. 63. Algunos californios protestaron públicamente contra la discriminación de chinos y afroamericanos. Véase BenAvides, "Californios". 
La función y sentido de estas leyes se concretaría en su ejecución y, de manera quizá más trascendental, en la jurisprudencia. En 1859, la Suprema Corte de Nuevo México accedió, con renuencia, a atraer el caso de un hombre acusado de homicidio que argüía no poder ser indiciado porque uno de los miembros del jurado no era ciudadano estadounidense. El tribunal asumió entonces la "pesada responsabilidad" de determinar la cuestión de la "retención del carácter de ciudadano mexicano" que durante 13 años había "perturbado y excitado” a la población del territorio. ${ }^{72}$ En el marco de la conflictiva política que acompañó la transformación de Estados Unidos en potencia continental, y a pesar de que el tratado establecía las reglas básicas para la integración de los antiguos mexicanos a la nación vencedora, los términos de su inserción siguieron siendo, durante largo tiempo, ambivalentes e inestables. El asunto se volvía especialmente contencioso cuando tocaba a la población indígena. Como se ha visto ya, los indios que imaginaban quienes no lo eran -el indio patriota y republicano o, las más veces, el “salvaje” que aterrorizaba a las poblaciones de la frontera-, y no los sujetos históricos concretos, daban forma a normas y práctica sobre el terreno. El estatus legal de los indígenas en los territorios conquistados sería cuestionado una y otra vez.

Al convertirse los territorios perdidos en parte de Estados Unidos, sus tribunales dirimirían, en casos individuales, pleitos de distinta naturaleza, en los que, para obtener ventaja, alguna de las partes cuestionaba el lugar de los antiguos mexicanos en el nuevo orden. La pervivencia del “carácter de mexicano" se erigió en elemento contencioso en las luchas por el poder político, en procesos civiles y penales y en disputas en torno al acceso a recursos: se desplegaría como estrategia legal para desarmar o paralizar al rival político o económico, o para obligar a un actor -y a sus bienes- a permanecer en el mercado.

72 Carter v. Territory, 1859, 1 N.M. 317. 
En la arena de la justicia contenciosa, algunos litigantes arguyeron que quienes habían sido mexicanos no podían haberse convertido en "ciudadanos americanos" sin más, con sólo esperar un año. No podían, por lo tanto, servir en jurados, ni como jueces. En California en 1870, por ejemplo, se declaró inválida la elección como juez de distrito de Pablo de la Guerra, por no ser ciudadano estadounidense. El agraviado, que como sabemos había sido miembro de la asamblea constituyente, y posteriormente senador local y vicegobernador del estado (1861-1862), defendió su pertenencia a la comunidad política ante la Suprema Corte del estado. Los abogados del demandado, el funcionario del gobierno estatal M. M. Kimberly, que había declarado nula la elección de De la Guerra, alegaron que las estipulaciones de un tratado no podían acometer una transformación de este calibre. El poder que estaba facultado para negociar tratados -el Ejecutivo- era "incompetente para naturalizar". Constitucionalmente, los ciudadanos nacían o se naturalizaban, y la naturalización era un proceso establecido por el congreso y que solo podía ratificar un juez, capaz de ponderar la idoneidad de cada solicitante. ${ }^{73}$

Los litigantes arguyeron que, conscientes de la ineptitud para convertirse en ciudadanos estadounidenses de la mayoría de los mexicanos -racial, religiosa y políticamente tan sospechosos-, el Senado había reformado la versión original del tratado, introduciendo en el artículo IX un lenguaje "muy distinto" al de los tratados con Francia y España, para establecer que los mexicanos que hubieran elegido convertirse en ciudadanos estadounidenses no lo harían sino hasta que llegara "el momento adecuado (a juicio del Congreso de los Estados Unidos)". Décadas después, los representantes del pueblo estadounidense no habían-intencionalmente, insistían los querellantes- establecido

73 People ex rel. Kimberly v. De la Guerra, 40 Cal 311 (1870). Agradezco a los doctores Pablo Mijangos y Rebecca Scott, que generosamente me proporcionaron el material sobre este proceso judicial. 
mecanismo alguno para cumplir con esta prescripción del tratado. ${ }^{74}$ Los mexicanos que, como De la Guerra, habían elegido no conservar "el carácter de ciudadanos de la República Mexicana” eran, simplemente, individuos que habían escogido convertirse en ciudadanos estadounidenses, eventualmente y de la manera que prescribiera el legislativo federal.

Arguyeron además que, a diferencia de los estados soberanos que habían fundado la Unión, e incluso de Texas, que como república independiente se había unido a los Estados Unidos por voluntad propia, los mexicanos residentes en el antiguo "departamento de California" no habían formado parte de una “soberanía independiente": los “derechos de los estados”, tan importantes en el sistema político estadounidense, eran "desconocidos” en México. ${ }^{75}$ Los antiguos mexicanos, por lo tanto, carecían de las tradiciones y del material genético, pero sobre todo del mecanismo legal para convertirse en ciudadanos estadounidenses, a pesar de que algunos se hubieran comportado como tales.

Los abogados de De la Guerra rechazaron estos argumentos. Al tiempo que admitían que la ciudadanía se limitaba a la membresía en el cuerpo político, y que no otorgaba automáticamente derechos políticos como el voto, afirmaban que no podía cuestionarse la "buena fe" con la que, durante años, hombres como De la Guerra habían desempeñado los deberes de la ciudadanía, y con la que habían sido reconocidos como miembros de la comunidad política por sus conciudadanos. La admisión de California como estado de la Unión representaba un acto explícito de reconocimiento de sus habitantes como ciudadanos de Estados Unidos, pues era aberrante pensar que en 1850 sólo los ciudadanos estadounidenses - muchos recién llegados- que

74 In the Supreme Court [...] Appellants, Eugene Lies, of Counsel, San Francisco, Women's Cooperative Union Print, 1870, pp. 11, 15-18.

75 In the Supreme Court [...] Appellants, p. 20. 
vivían en el territorio eran quienes componían, exclusivamente, el pueblo de California. ${ }^{76}$

Además, un tratado internacional, ratificado por el Senado, se convertía en la "ley de la tierra". No sólo se erigía en norma vigente en Estados Unidos; era un acuerdo con México en el que se había plasmado, de forma solemne, "no una promesa, sino una concesión". ${ }^{77}$ Por definición, el tratado obligaba a ambas partes a acatar sus disposiciones. Los magistrados de la Suprema Corte de California se negaron a indagar las características que requería la adquisición de la ciudadanía estadounidense. Se centraron en cambio en el compromiso contractual que implicaba la ratificación del Tratado de Guadalupe Hidalgo: no podía "admitirse duda alguna” de que éste debía “operar directamente, y por sí fijar el estatus" de los habitantes de los territorios adquiridos en 1848. Reconocieron también que, al incorporarse California a la Unión, quienes constituían su pueblo debían ser admitidos "a los plenos derechos de ciudadanos de los Estados Unidos". Quedaban bajo la protección del gobierno federal. El viejo político de Santa Bárbara - próspero, distinguido y blanco- era "claramente un ciudadano". ${ }^{78}$

En 1859, en Nuevo México, en donde no operaba el argumento sobre la erección del territorio en estado como acto explícito de ciudadanización federal, el tribunal superior territorial fue incluso más lejos en sus argumentos. Como se ha mencionado ya, George Carter, sentenciado por el asalto y muerte de Juan Duro, alegó que debía anularse la decisión judicial en su contra, pues uno de los miembros del jurado no era ciudadano. En contra de lo que el mismo tribunal había sentenciado unos años antes -en Quintana vs. Tomkins, en 1853-, los jueces afirmaron que Anastacio Sandoval, que diez años antes había

\footnotetext{
76 In the Supreme Court [...] Respondent, pp. 15, 18.

77 People ex rel. Kimberly v. De la Guerra.

78 People ex rel. Kimberly v. De la Guerra.
} 
firmado una declaración para conservar su "carácter mexicano", era, a pesar de todo, ciudadano estadounidense. ${ }^{79}$ Arguyeron que Sandoval había firmado en tiempos revueltos, cuando Ramón Ortiz, "sacerdote popular y poderoso", estaba alborotando "los prejuicios del pueblo" en contra del nuevo gobierno, con el objetivo de que emigraran a México. La declaración de Sandoval, aunque se conservaba en un archivo público, no era prueba suficiente de su extranjería: no se sabía “en dónde, ni cuándo, ni bajo qué circunstancias" había firmado, ni si lo había hecho frente a algún funcionario del poder judicial que pudiera dar fe de la autenticidad de este acto y de si lo había efectuado en libertad. 80

Así, la "fragilidad" de este testimonio escrito no podía "poner en peligro" los derechos de un ciudadano. A diferencia de lo que sugería esta endeble evidencia, Sandoval había permanecido en el territorio, sin hacer efectiva su elección "a favor de México". Había cumplido con sus obligaciones como ciudadano. Esto era prueba fehaciente de su sólido compromiso con Estados Unidos. Frente a sus acciones, "ni una ni cien declaraciones de intención" podían probar que era ciudadano mexicano "ni de hecho, ni por ley". Como los magistrados del tribunal californiano, los del nuevomexicano insistirían en que un tratado era un compromiso "sagrado e inviolable", aunque se hubiera contraído con un Estado "débil, mal gobernado y distraído" como México. El respeto a estos contratos era especialmente importante para Estados Unidos, "cuya existencia misma” dependía "del consentimiento mental y moral", de "acuerdos formales y deliberados". La autoridad que engendraban los contratos era uno de los pilares del sistema que había transformado a Estados Unidos "en una nación entre los poderes de la tierra".

\footnotetext{
${ }_{79}$ Carter v. Territory, 1859-NMSC-009, 1 N.M. 317 (S. Ct. 1859); Quintana v. Tomkins, 1, 1853 NMSC 2.

${ }^{80}$ Carter v. Territory.
} 
Para resolver algunos de los casos que afectaban a la población indígena y su derecho a "tomar, poseer y transmitir" propiedad raíz (United States vs. Ritchie (1854)), o de permanecer fuera del alcance del Buró de Asuntos Indígenas (Lucero), los tribunales en California y Nuevo México se apoyaron en una versión estratégica de la historia de la población indígena en México. Justificaron sus decisiones alegando que los indios mexicanos eran distintos a los que conocían los estadounidenses: sedentarios, "civilizados, pacíficos y amables". Recordaron con lirismo que la población "aborigen" había luchado por la independencia de España, y exaltaron los méritos personales, la solvencia moral y la productividad de los indios "civilizados", a pesar de que, como "raza", los indígenas fueran ignorantes y degradados. ${ }^{81}$

Esta visión positiva de los indígenas mexicanos no era, al parecer, compartida por los legisladores californianos. En 1850 promulgaron una ley para "el gobierno y la protección de los indios" que no reconocía a los indios como propietarios de la tierra que ocupaban y permitía a los pobladores blancos explotar el trabajo de los niños y mujeres indígenas que les eran "voluntariamente" confiados como pupilos, así como el de hombres adultos, condenados por "vagar, merodear, pedir limosna o frecuentar lugares en donde se vende alcohol", que debían trabajar para quien hubiera pagado su fianza hasta que ésta estuviera cubierta. Paradójicamente, estas visiones encontradas apuntalaban el mismo objetivo: poner a los indígenas -sus tierras y su fuerza de trabajo- al servicio del potente mercado californiano y mantener la relación con los pueblos indios en manos de las autoridades estatales, libre de la intervención de las autoridades federales,

${ }^{81}$ United States v. Ritchie 58 U.S. 525 (1854); 1 N.M. 422 United States v. José Juan Lucero (1869). 
constitucionalmente responsables de la relación con las "naciones domésticas dependientes" ${ }^{82}$

La ciudadanía es una categoría central de la política republicana moderna: estructura la relación entre el gobierno y los gobernados, dentro de un marco conceptual en que se supone que los ciudadanos constituyen, colectivamente, el epicentro de la soberanía. No obstante, no representa -difícilmente podía representar- un objeto fijo y transparente. Las mutaciones de la ciudadanía durante y después de la guerra entre México y Estados Unidos ponen de manifiesto que el normar la membresía en el cuerpo político y los derechos ciudadanos fue un proceso contencioso, prolongado, inconsistente e inacabado. ${ }^{83} \mathrm{Al}$ convertirse el Lejano Norte mexicano en el Soutbwest estadounidense, al transformarse la aislada Alta California en estado de la Unión y escenario de la fiebre del oro, definir el estatus legal y político de sus habitantes no resultó de una sencilla traducción de las iniciativas, visiones y cultura política del soberano en leyes. La transformación de mexicanos en estadounidenses estuvo sujeta a negociaciones diplomáticas y a las intervenciones de cuerpos representativos. También tuvo que definirse sobre el terreno, siguiendo, en algunos casos, una lógica binaria que oponía a amigos con enemigos. Una vez que terminó la guerra, la pertenencia política se convirtió a menudo, del otro lado de la nueva frontera, en una palanca dentro de las disputas políticas y económicas locales. La construcción de la ciudadanía como fenómeno histórico es compleja y desconcertante; son sus contradicciones y variaciones las que arrojan luz sobre la política del pasado.

82 "An Act for the Government and Protection of Indians" (cap. 133, Statutes of California, 22 de abril de 1850); véase también Magliari, "Free Soil”; "Free State".

83 Novak, “The Legal”. 


\section{REFERENCIAS}

Algunos documentos sobre el Tratado de Guadalupe y la situación de México durante la invasión americana, Antonio de la Peña y Reyes (comp.), México, Secretaría de Relaciones Exteriores, 1930.

Benavides, José Luis, “Californios! Whom Do You Support? 'El Clamor Público's' Contradictory Role in the Racial Formation Process in Early California”, en California History, 84: 2 (2006/2007), pp. 56-66.

Berge, Dennis E., “A Mexican Dilemma: The Mexico City Ayuntamiento and the Question of Loyalty, 1846-1848”, en The Hispanic American Historical Review, 50: 2 (1970), pp. 229-256.

BRINGAs NosTTI, Raúl, La regeneración de un pueblo pestilente: la anexión de México a Estados Unidos (1846-1848), México, Miguel Ángel Porrúa, 2008.

Buve, Raymond y Romana Falcón (coords.), El México profundo en la gran década de la desesperanza (1846-1856), Puebla, Benemérita Universidad Autónoma de Puebla, Ediciones EyC, 2016.

Castillo Nájera, Francisco, El Tratado de Guadalupe:ponencia al Congreso Mexicano de Historia, México, Talleres Gráficos de la Nación, 1947.

Ceballos Ramírez, Manuel (coord.), Encuentro en la frontera: mexicanos y norteamericanos en un espacio común, México, El Colegio de México, Tijuana, El Colegio de la Frontera Norte, Ciudad Victoria, Universidad Autónoma de Tamaulipas, 2001.

Chacón Gómez, Fernando, “The intended and actual effect of article VIII of the Teatry of Guadalupe Hidalgo: Mexican treaty rights under international and domestic law", tesis de doctorado en historia, Michigan, University of Michigan, 1977.

Clark, Emily, Ibrahima Thioub y Cécile Vidal (eds.), New Orleans, Louisiana, and Saint-Louis, Senegal: Mirror Cities in the Atlantic World, 1659-2000s, Baton Rouge, Louisiana State University Press, 2019.

Cosgrave, George, “A Diplomatic Incident on the Little Mariposa”, en California Historical Society Quarterly, 21: 4 (1942), pp. 358-362.

Crutchfield, James A., Revolt at Taos: The New Mexican and Indian Insurrection of 1847, Yardley, Pa., Westholme Publishing, 2015. 
Delay, Brian, War of a Thousand Suns: Indian Raids and the Mexican American War, New Haven, Yale University Press, 2008.

De León, Arnoldo, They Called Them Greasers: Anglo Attitudes toward Mexicans in Texas, 1821-1900, Austin, University of Texas Press, 1983.

Downs, Gregory P. y Kate Masur (eds.), The World the Civil War Made, Chapel Hill, The University of North Carolina Press, 2015.

Examen de los delitos de infidelidad a la Patria imputados a los españoles sometidos baxo la dominación francesa, Cádiz, Imprenta de la Sra. Viuda de Duprat, 1816.

Falcón, Romana, "En medio del asedio bélico. Defensas institucionales, resistencias y rebeliones de los pueblos del centro y sur del país, 1846-1856", en Buve y Falcón (coords.), 2016, pp. 143-170.

Flores, Justo, Soberanía y excepcionalidad: la integración de la peninsula de Yucatán al estado mexicano, 1821-1848, México, El Colegio de México, 2017.

Francaviglia, Richard V. y Douglas W. Richmond (eds.), Dueling Eagles. Reinterpreting the US-Mexican War, 1846-1848, Fort Worth, Texas Christian University Press, 2000.

Gonzales, Phillip B., "Mexican Party, American Party, Democratic Party. Establishing the American Political Party in New Mexico, 1848-1853", en New Mexico Historical Review, 88: 3 (2013), pp. 253-285.

Gonzales-Berry, Erlinda y David R. Maciel (eds.), The Contested Homeland: A Chicano History of New Mexico, Albuquerque, University of New Mexico Press, 2000.

GonZÁlez de la VARA, Martín, "El traslado de familias al norte de Chihuahua y la conformación de una región fronteriza, 1848-1854”, en Frontera Norte, vI: 11 (1994), pp. 9-24.

González de la Vara, Martín, "La rebelión de los cañaderos en Nuevo México, 1837-1838”, en Cuicuilco, 7 (18) (2000), pp. 223-256.

Granados, Luis Fernando, Sueñan las piedras. Alzamiento ocurrido en la ciudad de México, 14, 15 y 16 de septiembre de 1847, México, Era, 2005. 
Greenberg, Amy S., A Wicked War. Polk, Clay, Lincoln and the 1846 US Invasion of Mexico, Nueva York, Vintage, 2013.

Griswold del Castillo, Richard, The Treaty of Guadalupe Hidalgo. A Legacy of Conflict, Norman, University of Oklahoma Press, 1990.

Guardino, Peter, The Dead March. A History of the Mexican American War, Cambridge, Harvard University Press, 2017.

Haynes, Sam W. y Gerald D. Saxon (eds.), Contested Empire. Rethinking the Texas Revolution, College Station, Texas A\&M University Press, 2015.

Hernández, José Ángel, Mexican American Colonization during the Nineteenth Century. A History of the US-Mexico Borderlands, Nueva York, Cambridge University Press, 2012.

Herrera, Carlos R., "New Mexico Resistance to U.S. Occupation during the Mexican American War of 1846-1848", en GonZales-Berry y Maciel (eds.), 2000, pp. 23-42.

Herrera Serna, Laura (coord.), México en guerra, 1846-1848. Perspectivas regionales, México, Conaculta, 1997.

In the Supreme Court of the State of California. The People of the State of California ex. rel. M.M. Kimberly us Pablo De la Guerra. A. Packard, attorney for the Appellants, Eugene Lies, of Counsel, San Francisco, Women's Cooperative Union Print, 1870.

In the Supreme Court of the State of California. The People of the State of California ex rel. M.M. Kimberly vs. Pablo De la Guerra. Peachy and Hubert, Of Counsel for the Respondent, San Francisco, E. Bosqui and Co., Printers, 1870.

Jacobs, Meg, William J. NovaK y Julian E. Zelizer (eds.), The Democratic Experiment. New Directions in American Political History, Princeton, Princeton University Press, 2003.

Levinson, Irving W., Wars within War: Mexican Guerrillas, Domestic Elites, and the United States of America, 1846-1848, Fort Worth, Texas Christian University, 2005.

Magliari, Michael, "Free Soil, Unfree Labor: Cave Johnson Couts and the Binding of Indian Workers in California, 1850-1867", en Pacific Historical Review, 73: 3 (2004), pp. 349-390. 
MagLiari, Michael, "Free State Slavery: Bound Indian Labor and Slave Trafficking in California's Sacramento Valley, 1850-1864", en Pacific Historical Review, 81: 2 (2012), pp. 155-192.

Martínez, Óscar J., "Los dos Laredos: historia compartida y experiencia de la frontera”, en Ceballos Ramírez (coord.), 2001, pp. 233-257.

McNierney, Michael (ed.), Taos 1847: The Revolt in Contemporary Accounts, Boulder, Johnson Publishing Co., 1980.

Molina, Daniel, La pasión del padre Jarauta, México, Gobierno de la Ciudad de México, 1999.

Montejano, David, Anglos and Mexicans in the Making of Texas, 1836-1986, Austin, University of Texas Press, 1987.

Morgan, Edmund S., Inventing the People. The Rise of Popular Sovereignty in England and America, Nueva York, WW Norton, 1988.

Moyano, Ángela, La resistencia de las Californias a la invasión norteamericana (1846-1848), México, Conaculta, 1992.

Moyano, Ángela, “La invasión norteamericana, 1846-1848”, en Piñera RAMíreZ (coord.), 1994, t. I, pp. 97-122.

New Mexico. Convention of Delegates. Journal and Proceedings, House of representatives, $31^{\text {st }}$ Congress, $1^{\text {st }}$ Session, Miscellaneous $N^{\circ} 39$.

Novak, William J., "The Legal Transformation of Citizenship in NineteenthCentury America", en Jacobs, NovaK y Zelizer (eds.), 2003, pp. 85-119.

Palti, Elías J., El tiempo de la política: el siglo XIX reconsiderado, Buenos Aires, Siglo Veintiuno Editores, 2007.

Piñera Ramírez, David (coord.), Visión histórica de la frontera norte de México, Tijuana, Universidad Autónoma de Baja California, 1994, 3 tomos.

PITT, Leonard, Decline of the Californios: A Social History of the SpanishSpeaking Californias, 1846-1890, Berkeley, University of California Press, 1999.

Pubols, Louise, The Father of All. The De la Guerra Family, Power, and Patriarchy in Mexican California, Berkeley, Huntington Library, University of California Press, 2010. 
PurCell, Fernando, ;Muchos extranjeros para mi gusto! Mexicanos, chilenos e irlandeses en la construcción de California, 1848-1880, Santiago, Chile, Fondo de Cultura Económica, 2016.

Report of the Debates of the Convention of California on the Formation of the State Constitution, in September and October 1849, Washington, John T. Towers, 1850.

Reséndez, Andrés, "Getting Cured and Getting Drunk: State versus Market in Texas and New Mexico, 1800-1850", en Journal of the Early Republic, 22: 1 (primavera 2002), pp. 77-103.

Reséndez, Andrés, Changing National Identities at the Frontier, 1800-1850, Cambridge, Cambridge University Press, 2004.

Reséndez, Andrés (ed.), A Texas Patriot on Trial in Mexico: José Antonio Navarro and the Texan Santa Fe Expedition, Dallas, DeGolyer Library, Clements Center for Southwest Studies, 2005.

SABATO, Hilda, La política en las calles: entre el voto y la movilización. Buenos Aires, 1862-1880, Buenos Aires, Sudamericana, 1998.

Sánchez de TAGLe, Esteban, "1847. Un protectorado americano para la Ciudad de México”, en Relaciones, 22: 86 (2001), pp. 211-248.

Schlereth, Eric S., "Privileges of Locomotion: Expatriation and the Politics of Southwestern Border Crossing", en The Journal of American History (2014), pp. 995-1020.

Schlereth, Eric S., "Voluntary Mexicans. Allegiance and the Origins of the Texas Revolution”, en Haynes y SAXon (eds.), 2015, pp. 13-41.

ScoтT, Rebecca J., “Asserting Citizenship and Refusing Stigma. New Orleans Equal-Rights Activists Interpret 1803 and 1848”, en CLARK, Thioub y VIDAL (eds.), 2019, pp. 146-167.

Sierra O'Reilly, Justo, Diario de nuestro viaje a los Estados Unidos (la pretendida anexión de Yucatán), México, Porrúa e hijos, 1938.

Sмiтh, Stacey L., "Emancipating Peons, Excluding Coolies: Reconstructing Coercion in the American West”, en Downs y Masur (eds.), 2015, pp. 46-74.

Sordo Cedeño, Reynaldo, "El Congreso y la guerra con Estados Unidos, 1846-1848”, en VÁzQUEZ (coord.), 1997, pp. 47-103. 
Sт. John, Rachel, “The Unpredictable America of William Gwin: Expansion, Secession and the Unstable Borders of Nineteenth Century North America", en The Journal of the Civil War Era, 6: 1 (2016), pp. 56-84.

SuÁrez Iriarte, Francisco, Defensa pronunciada ante el gran jurado el 21 de marzo de 1850, por [...], acusado en 8 de agosto de 1848 por el Secretario de Relaciones en aquella fecha, de los crímenes de sedición contra el Gobierno de Querétaro e infidencia contra la patria, en sus actos como presidente de la asamblea municipal de la Ciudad y Distrito de México, México, Tipografía de R. Rafael, 1850.

Tinker Salas, Miguel, “Los dos Nogales”, en Ceballos Ramírez (coord.), 2001, pp. 259-279.

Van Wagenen, Michael, The Forgotten War: The Enduring Legacies of the US-Mexican War, Amherst, University of Massachusetts Press, 2012.

VÁzQueZ, Josefina Z., "El origen de la guerra con Estados Unidos”, en Historia Mexicana, XLVII: 2 (186) (oct.-dic 1997), pp. 285-309.

VÁzquez, Josefina Z., La intervención norteamericana, 1846-1848, México, Secretaría de Relaciones Exteriores, 1997.

VÁzquez, Josefina Z. (coord.), México al tiempo de su guerra con Estados Unidos, 1846-1848, México, Fondo de Cultura Económica, El Colegio de México, 1997.

Weber, David J., Foreigners in their Native Land: Historical Roots of the Mexican Americans, Albuquerque, University of New Mexico Press, 1973. 